\title{
GESTIÓN DEL CONOCIMIENTO: ORÍGENES Y EVOLUCIÓN
}

\section{Knowledge management: origins and evolution}

\section{Mario Pérez-Montoro}

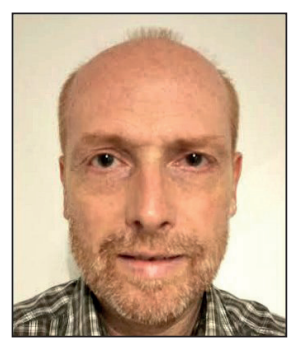

Mario Pérez-Montoro es doctor en filosofía y ciencias de la educación por la Universitat de Barcelona y posgraduado en organización de sistemas de documentación por la Universitat Politècnica de Catalunya. Ha realizado estudios de postgrado en el Instituto di Discipline della Comunicazione de la Universitá di Bologna (Italia), y ha sido profesor visitante del CSLI (Center for the Study of Language and Information) de la Stanford University (California, EUA) y de la School of information de la UC Berkeley (California, EUA). Investiga sobre arquitectura y visualización de la información. Ha publicado los libros: The phenomenon of information (Scarecrow Press, 2007), Arquitectura de la información en entornos web (Trea, 2010), y junto a Lluís Codina, Navigation design and SEO for content-intensive websites: A guide for an efficient digital communication (Elsevier Chandos, 2016), entre otros. Es profesor del Departamento de Biblioteconomía, Documentación y Comunicación Audiovisual de la Universitat de Barcelona.

http://orcid.org/0000-0003-2426-8119

Universitat de Barcelona, Departament de Biblioteconomía, Documentación y Comunicación Audiovisual Melcior de Palau, 140. 08014 Barcelona, España perez-montoro@ub.edu

\section{Resumen}

Desde sus orígenes, la disciplina de la gestión del conocimiento ha experimentado una evolución particular, arrancando con fuerza en un primer momento, presentando un sólido desarrollo posterior, pero viviendo actualmente un lánguido estancamiento. En este trabajo se analiza ese itinerario. Para cubrir este objetivo presentamos el contexto fundacional de la disciplina, para, seguidamente, revisar la evolución de la misma a través de varios indicadores como el interés que despierta en las últimas décadas y la producción científica anual (monografías y artículos de revistas indizadas). También se describe el ecosistema de la formación universitaria centrada en la gestión del conocimiento.

\section{Palabras clave}

Gestión del conocimiento; Orígenes; Evolución; Interés general; Producción científica; Formación universitaria.

\section{Abstract}

Since its origins, the discipline of knowledge management has had a unique evolution: going strong at first, followed by solid development, but currently falling into languid stagnation. In this paper we analyze this trajectory by describing the founding context of the discipline and reviewing its evolution using two indicators, the heightened interest in recent decades and the annual scientific production (monographs and articles in indexed journals). Finally, the ecosystem of university training that is focused on knowledge management is described.

\section{Keywords}

Knowledge management; Origins; Evolution; General interest; Scientific production; University education.

Pérez-Montoro, Mario (2016). “Gestión del conocimiento: orígenes y evolución”. El profesional de la información, v. 25, n. 4, pp. 526-534.

\section{Introducción}

Corrían los años finales de la década de los 90 del siglo pasado cuando unos académicos universitarios publicaron en forma de coautoría dos obras (Nonaka; Takeuchi, 1995; Davenport; Prusak, 1998) que cimentarían los conceptos principales de una nueva disciplina emergente en ese momento: la gestión del conocimiento. Ya desde sus inicios se entendió como una disciplina encargada de diseñar e implementar sistemas cuyo objetivo es identificar, capturar y compartir sistemáticamente el conocimiento involucrado dentro de una organización de forma que pueda ser convertido en valor para la misma.

Han pasado ya casi 20 años desde ese momento bibliográfico fundacional y la disciplina ha podido experimentar una 
evolución particular, arrancando con fuerza en un primer momento, presentando un sólido desarrollo posterior, pero viviendo actualmente un lánguido estancamiento.

En este trabajo analizamos ese itinerario. Primeramente presentamos el contexto fundacional de la disciplina, para, a continuación, revisar su evolución a través de dos indicadores:

- interés que despierta en las últimas décadas;

- producción científica anual (monografías y artículos de revistas indizadas).

Finalmente se describe el ecosistema de la formación universitaria centrada en gestión del conocimiento.

La gestión del conocimiento es la disciplina encargada de diseñar e implementar sistemas con el objetivo de identificar, capturar y compartir el conocimiento de una organización de forma que pueda ser convertido en valor para la misma

\section{Orígenes}

A partir de la Segunda Guerra Mundial algunas empresas comienzan a desarrollar una serie de estrategias para mejorar su producción basadas en el aprendizaje a partir de la experiencia. Tienen su máxima expresión teórica en la obra del economista Kenneth Arrow (1962). Algunos autores (Prusak, 2001; Senge, 1990) han visto en estas estrategias un claro antecedente intelectual del movimiento de la gestión del conocimiento.

Sin embargo, este movimiento se extiende y se consolida de forma definitiva en la segunda mitad de los 90 . No existe un solo factor que pueda justificar por sí mismo el escenario que ha generado el nacimiento de esta disciplina. Pero existen dos variables, una tecnológica y otra con un carácter más directamente económico, que pueden justificar ese escenario:

- han ido apareciendo una serie de tecnologías de la información y de la comunicación que han permitido el acceso, la gestión y el uso intensivo de información y conocimiento hasta niveles nunca antes conocidos;

- se ha consolidado un nuevo entorno económico de globalización de los mercados y una nueva cultura de la competitividad (Gorey; Dobat, 1996). En ese escenario, el conocimiento y los activos intangibles - no sólo los materiales - de las empresas comienzan a entenderse como ese valor añadido que puede garantizar el correcto funcionamiento y la supervivencia de las mismas en los mercados globalizados (Stewart, 1997; Leonard-Barton, 1995; Sveiby, 1997).

En ese contexto fundacional, cristalizaron dos escuelas que darían lugar a las dos maneras de entender la disciplina de la gestión del conocimiento:

1) Se entiende el conocimiento como un proceso, como lo denomina Karl Sveiby (2001). Es la escuela oriental (o ja- ponesa) - derivada de las ideas defendidas, entre otros, por Nonaka y Takeuchi (1995), por citar algunas cabezas visibles - y centra sus investigaciones en el conocimiento tácito y su creación. Se nutre de disciplinas teóricas como la psicología, sociología y pedagogía. Dentro de esta escuela o knowledge-process group, se concibe la empresa no de una manera mecanicista sino como un organismo vivo que interacciona con el entorno. En este contexto, el conocimiento se entiende más como un proceso psicológico, relacionándolo con la experiencia. Se defiende la posibilitación del conocimiento y su socialización como operaciones centrales para la gestión del mismo (Nonaka, 1991; Nonaka; Konno, 1998). Dentro de este enfoque, las acciones encaminadas a la gestión del conocimiento suelen realizarse desde el departamento de recursos humanos.

2) La otra escuela entiende el conocimiento como un objeto, como lo denomina también Karl Sveiby (2001). Se trata de la escuela más occidental - derivada de las ideas defendidas por Davenport y Prusak (1998), por citar sólo un par de autores- y centra sus investigaciones en el conocimiento explícito y la gestión del mismo; nutriéndose de disciplinas teóricas como la teoría y la gestión de la información (Davenport, 1997). Dentro de esta segunda escuela o knowledge-object group se identifica la empresa como un mecanismo de procesar información. En este contexto, el conocimiento se entiende como una producción obtenida a partir de la gestión adecuada de la información y el valor del mismo se consigue cuando se logra transformar en conocimiento explícito representado en documentos que pueden ser tratados y gestionados. Dentro de este enfoque alternativo, las acciones encaminadas a la gestión del conocimiento suelen realizarse desde el departamento de sistemas y gestión de información.

Al comienzo de la gestión del conocimiento se distinguieron dos escuelas: la oriental, que trataba el conocimiento como proceso, y la occidental, que lo consideraba un objeto obtenido a partir de la información

Como cabía esperar, en la evolución de la disciplina, la tensión entre las dos escuelas se ha ido disipando y en el campo de la consultoría se combinan simultáneamente, y en una misma estrategia, las ventajas que ofrecen los dos enfoques implementando soluciones que van desde los recursos humanos a la gestión de la información, pasando por los desarrollos tecnológicos.

\section{Evolución}

Tras su consolidación en la década de los noventa, la disciplina ha presentado una evolución muy similar a otras propuestas científicas y de gestión introducidas en el pasado y que estuvieron de moda durante un tiempo. Ejemplos fueron la auditoría de la información, la vigilancia tecnológica, la inteligencia competitiva o la ecología de la información. De esta manera, tras un primer momento de explosión, la 


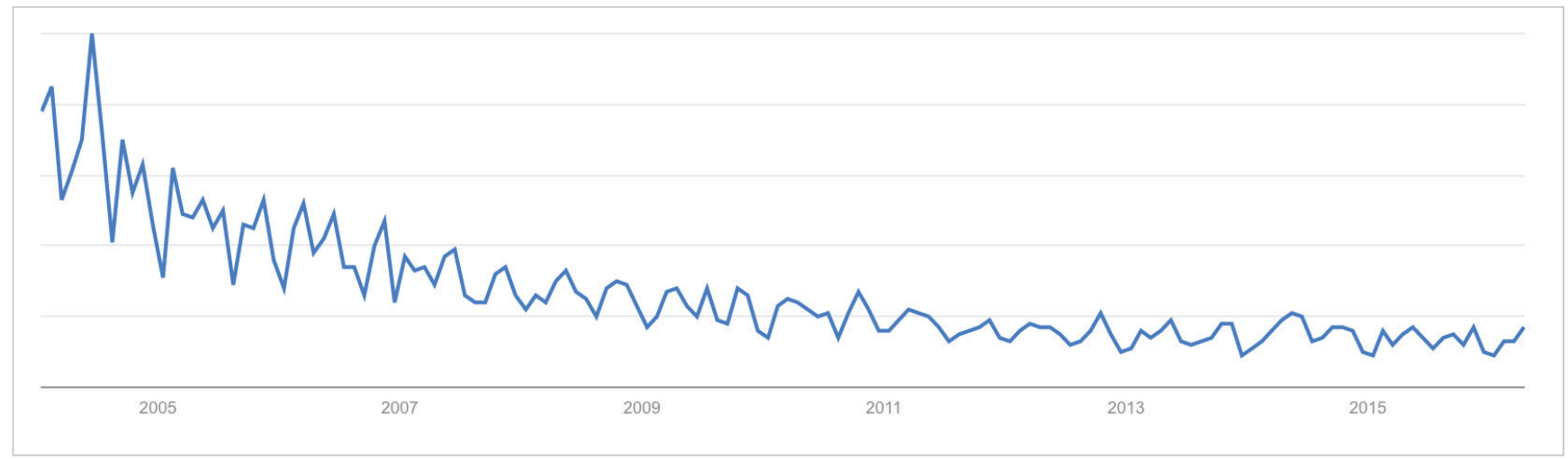

Figura 1. Gráfica asociada con la expresión "knowledge management" obtenida en Google Trends (junio 2016)

disciplina ha disfrutado de un período de expansión, para entrar más tarde en un estadio de paulatino descenso del interés generado.

Podemos encontrar varios indicadores que permiten dibujar ese escenario histórico expresado. Principalmente, indicadores obtenidos de la utilización de una serie de herramientas y conjuntos de datos que nos permiten visualizar los patrones evolutivos de la atracción despertada por un tema o disciplina concreta presentada a lo largo de un período de tiempo concreto.

Para recoger la evolución de esa atracción vamos a analizar cómo ha ido variando el interés general despertado por la disciplina, la producción científica anual (monografías y artículos de revistas indizadas) generada sobre la misma y la propuesta universitaria dirigida a formar a los profesionales en la gestión del conocimiento.

\subsection{Interés general}

Estudiar el interés por un tema determinado no es una tarea sencilla. Apostar por métodos de investigación participativos como la entrevista o el cuestionario puede ofrecer interesantes resultados, pero los costes y el tiempo requerido pueden hacer inviable el estudio.

Sin embargo, podemos apostar por métodos no participativos, más sencillos e indirectos. Así, por ejemplo, cuando alguien está interesado en un tema concreto acude a un buscador para informarse. Por tanto, podemos estudiar la evolución cuantitativa de las consultas realizadas en un buscador como un indicador de cómo ha evolucionado el interés general de la población por ese tema.

Google es, sin duda, el buscador más utilizado en el mundo para localizar información en internet. Dentro de las herramientas asociadas a ese buscador, la empresa ofrece Google Trends.

\section{https://www.google.com/trends}

Google Trends es un servicio gratuito online de Google que permite visualizar la popularidad o interés de búsqueda en internet de varias palabras y frases (hasta 5 términos de forma simultánea) a lo largo del tiempo (desde 2004 hasta la actualidad) respecto a una escala de 0 a 100. El principio que subyace es bien simple: cuantas más veces se escriban las palabras relacionadas con un tema en la caja de búsque- da de Google, mayor interés suscita el tema expresado por esa ecuación de búsqueda. Esta visualización nos ofrece la posibilidad de identificar los patrones y cambios de interés por el tema producidos en ese período o apreciar cómo varía según la zona geográfica. También suministra un mapa de calor geográfico que muestra gráficamente el índice del volumen de búsquedas en las distintas regiones de cada país y una lista de las palabras relacionadas con cada término buscado que presentan un mayor crecimiento.

Realizando la búsqueda con el término compuesto "knowledge management" en Google Trends se obtiene la gráfica recogida en la figura 1 . Según esta gráfica, el interés sobre esta disciplina presenta una línea dentada (o en forma de sierra) que muestra momentos de tiempo en los que éste aumenta alternados de manera cíclica con otros en los que disminuye. Sin embargo, en términos absolutos, la tendencia es que, tras un período de aumento de interés que culmina en 2004, el tema va perdiendo interés lineal y progresivamente a lo largo de los años hasta alcanzar las cuotas más bajas en la actualidad. De 2004, con un valor de interés por encima de 80 (sobre 100 posibles), ha pasado a presentar un valor de interés en 2016 por debajo de 15 (sobre 100 posibles).

Tras un primer momento de explosión, la disciplina ha disfrutado de un período de expansión, para entrar más tarde en un estadio de paulatino descenso del interés generado

Podemos visualizar también la evolución del interés por el tema de la gestión del conocimiento comparándolo con el interés que suscita otra disciplina emergente, la de los big data, que actualmente se presenta como uno de los temas más candentes tanto en contextos académicos como profesionales. Para realizar esa comparación, en Google Trends hemos añadido el segundo término compuesto "big data" (línea roja) a la primera búsqueda realizada con el término compuesto "knowledge management" (línea azul), obteniendo la gráfica recogida en la figura 2. Como se desprende de la gráfica, el interés por los big data, de la misma forma que por la gestión del conocimiento, presenta una línea dentada 


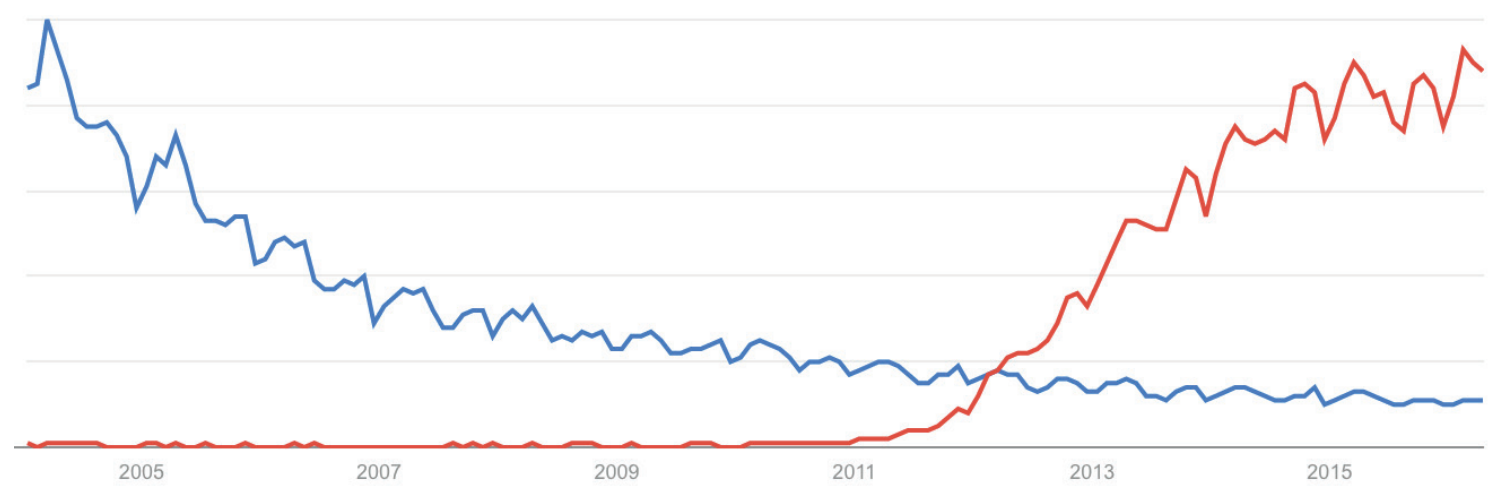

Figura 2. Gráfica asociada con las expresiones "knowledge management" (línea azul) y "big data” (línea roja) obtenida en Google Trends (junio 2016)

(aunque mucho menos escarpada) que muestra momentos de tiempo alternos en los que éste aumenta y otros en los que disminuye. Sin embargo, en términos absolutos, la tendencia es que, a partir de 2011, el interés por este tema se dispara de forma acusada hasta el día de hoy. En este sentido, en sólo 5 años, desde 2011, con un valor de interés cercano a 0 (sobre 100 posibles), ha pasado a presentar un valor de interés en 2016 por encima de 75 (sobre 100 posibles). Destaca también que a partir de 2012 el interés por los big data supera el mostrado por la gestión del conocimiento.

Este análisis se puede completar comparando el interés geográfico mostrado por ambas disciplinas. Así, si observamos la figura 3 podemos comprobar que entre los siete primeros países del ranking de interés sobre el tema de la gestión del conocimiento no se encuentra ninguno de los que lideren los avances científicos ni las propuestas innovadoras en el ámbito de la gestión. El ranking de siete países está liderado por Kenia (con un valor de interés de 100 (sobre 100 posibles) y lo cierra la India (con un valor de interés de 34 (sobre 100 posibles)), incluyendo en ese intervalo otros países como Sudáfrica, Sri Lanka, Malasia, Hong Kong y Singapur.

Sin embargo, si generamos la gráfica de los siete primeros países del ranking de interés sobre el tema de los big data (figura 4) el resultado es distinto. En este caso entre estos

\begin{tabular}{|l|l|}
\hline Kenia & 100 \\
\hline Sudáfrica & $63 \quad 56$ \\
\hline Sri Lanka & 50 \\
\hline Malasia & 43 \\
\hline Singapur & 43 \\
\hline India & 34 \\
\hline
\end{tabular}

Figura 3. Gráfica con las regiones que muestran mayor interés frente a la ecuación "knowledge management" obtenida en Google Trends (junio 2016) siete primeros países se encuentran Estados Unidos y Corea del Sur, dos de los países que lideran los avances científicotecnológicos. En esta gráfica también comprobamos que el ranking está liderado por la India (con un valor de interés de 100 (sobre 100 posibles)) y lo cierra Estados Unidos (con un valor de interés de 28 (sobre 100 posibles), incluyendo en ese intervalo otros países como Singapur, Hong Kong, Corea del Sur, Taiwán y Sri Lanka.

\subsection{Producción científica}

La producción científica sobre un tema puede ser identificada como un fiel indicador del interés que suscita una materia. Sin embargo, no siempre es así. La producción científica puede verse alterada por factores exógenos (líneas de investigación impuestas en convocatorias de financiación o intereses institucionales, por ejemplo, entre otras) que hagan variar el tema y el volumen producido en un período de tiempo concreto. Por estos factores, en momentos determinados se puede hablar de alguna manera de un cierto grado de "burbuja" académica alrededor de un tema. Pensemos, por ejemplo, cómo ha aumentado de forma casi lineal la producción científica sobre el tema de la web semántica en los últimos años y cómo paradójicamente ha disminuido, en cambio, el número de proyectos reales en los que se ha implementado esa tecnología (W3C, 2012).

\begin{tabular}{|l|l|}
\hline India & 100 \\
\hline Singapur & 71 \\
\hline Hong Kong & 60 \\
\hline Corea del Sur & 55 \\
\hline Taiwán & 48 \\
\hline Sri Lanka & 31 \\
\hline Estados Unidos & 28 \\
\hline
\end{tabular}

Figura 4. Gráfica con las regiones que muestran mayor interés frente a la ecuación "big data" obtenida en Google Trends (junio 2016) 


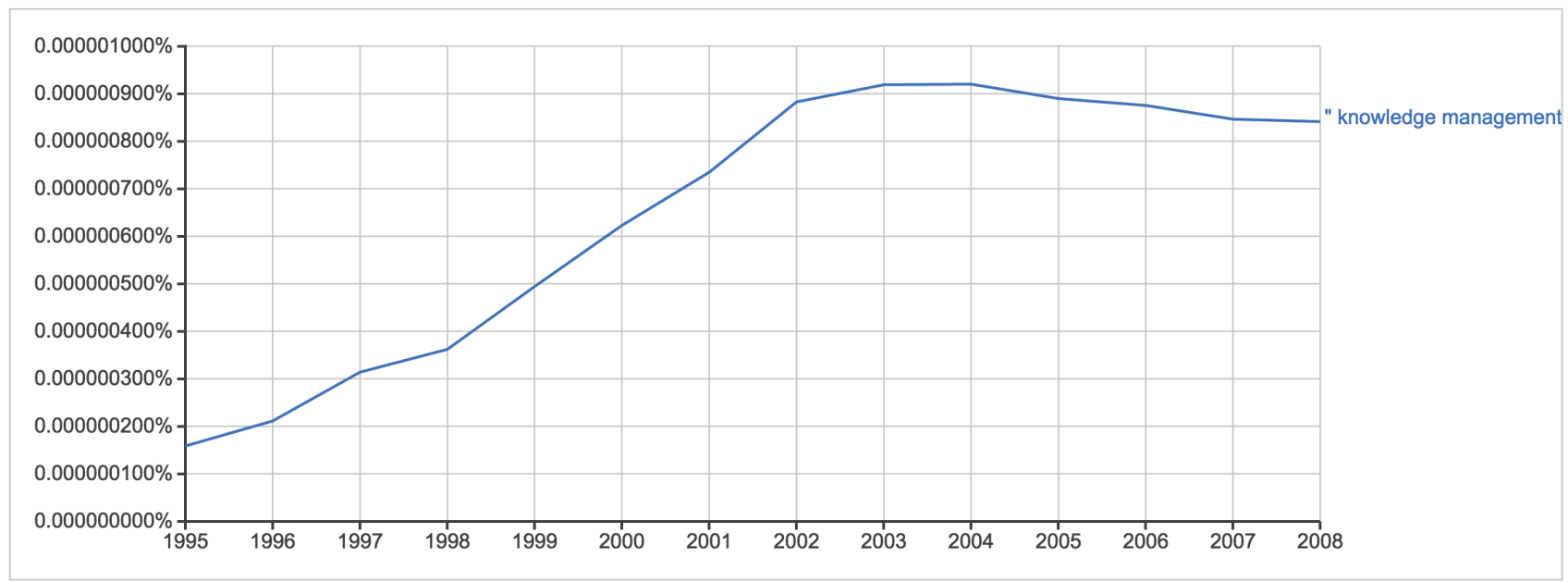

Figura 5. Gráfica asociada con la expresión "knowledge management" dentro del corpus lingüístico anglosajón, entre los años 1995 y 2008 , obtenida en Google Ngram Viewer (junio 2016)

Pero dejando al margen esos factores de distorsión, podemos utilizar la variación anual en la producción científica (monografías y artículos) sobre el tema de la gestión del conocimiento como un indicador de la evolución de esta disciplina.

\section{Producción de monografías}

Para poder analizar de forma cómoda la producción de monografías sobre el tema de la gestión del conocimiento podemos utilizar, de nuevo, otra propuesta de la familia de Google: Google Books Ngram Viewer. https://books.google.com/ngrams

Google Books Ngram Viewer es un servicio gratuito online de Google que permite visualizar la evolución de la producción de monografías (a las que Google tiene acceso a partir de su proyecto Google Books) sobre un tema concreto. Para entregarnos esa visualización representa en una gráfica de series temporales la evolución de la frecuencia de los términos de búsqueda (términos separados por comas o n-gramas, de ahí el nombre) en los libros indizados dentro del corpus lingüístico y a lo largo del rango de años elegidos.
Si realizamos una búsqueda con el término compuesto "knowledge management" dentro del corpus lingüístico anglosajón y entre los años 1995 y 2008 (límite superior que puede alcanzar el rango) en Google Ngram Viewer obtenemos la gráfica recogida en la figura 5. En ella podemos observar cómo, a partir de 1995, aumenta de forma casi lineal la producción de monografías que incluyen el término compuesto hasta 2002. De 2002 a 2004, aumenta un poco esa producción alcanzando su máximo valor. Pero es a partir de ese año cuando el número anual de libros sobre el tema comienza a decaer paulatinamente alcanzando su nivel más bajo en 2008 (el sistema no permite obtener esa evolución en los años posteriores), justo por debajo de los datos obtenidos en 2002.

Ese patrón de la evolución del tratamiento del tema en las monografías en lengua inglesa se reproduce también, aunque con un desfase de 2 años, en las monografías que incluyen el término "gestión del conocimiento" dentro del corpus de libros en español (figura 6). En este segundo caso, la evolución casi lineal arranca en 1997 y se extiende hasta 2004. Un año más tarde la producción se estanca para subir levemente hasta 2006. A partir de ese año y hasta 2008

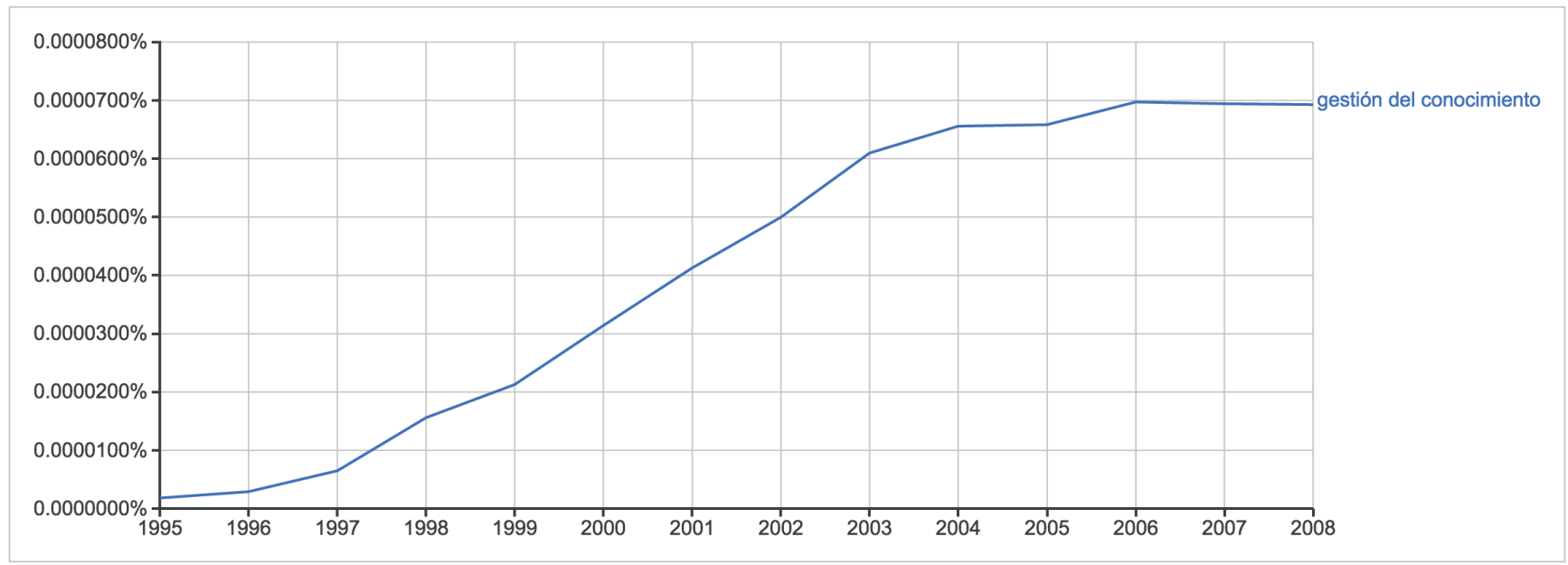

Figura 6. Gráfica asociada con la expresión "gestión del conocimiento" dentro del corpus lingüístico español, entre los años 1995 y 2008 , obtenida en Google Ngram Viewer (junio 2016) 


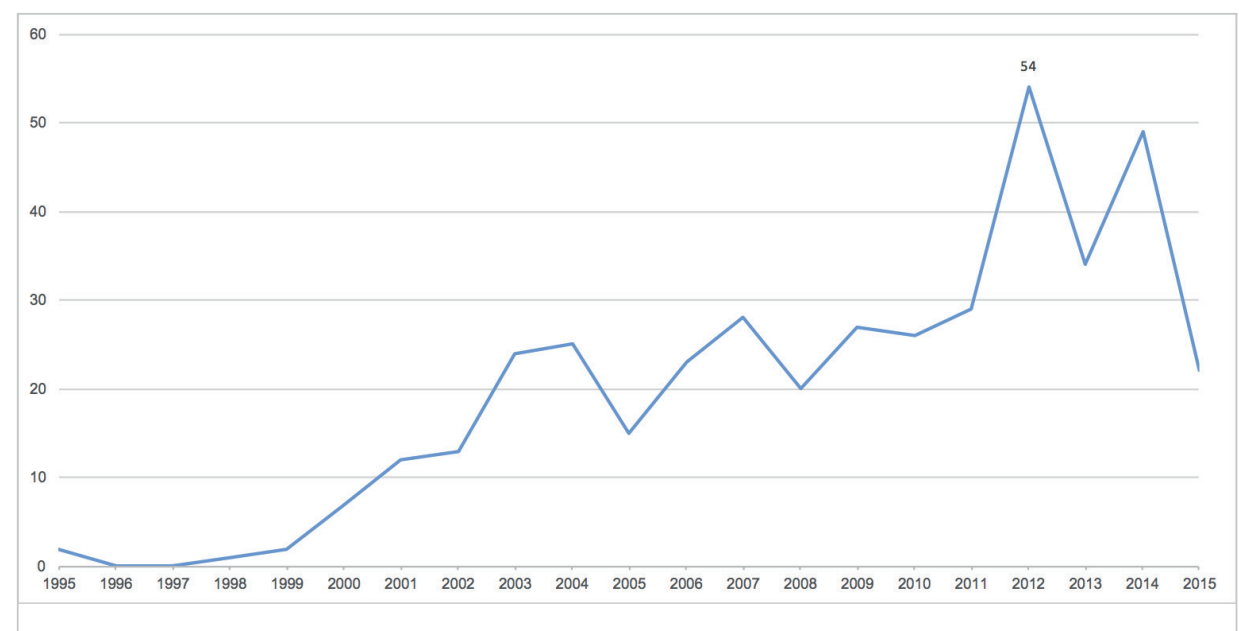

Figura 7. Gráfica de la evolución de monografías sobre gestión del conocimiento publicadas en España durante el período 1995-2015

(el sistema no permite obtener esa evolución en los años posteriores), el patrón apunta a un descenso paulatino de la producción.

La evolución global e internacional de la publicación de monografías dedicada al tema de la gestión del conocimiento (figura 6) contrasta, al menos en parte, con la evolución de esa misma producción centrada exclusivamente en el territorio español. Para realizar esa comparación podemos recurrir a la base de datos del ISBN de libros editados en España, publicada por el Ministerio de Educación, Cultura y Deporte.

Si realizamos una búsqueda con el término compuesto "gestión del conocimiento" en esa base de datos y los ordenamos por fecha de publicación descartando el año 2016, obtenemos que desde 1995 hasta finales de 2015 se han publicado en España 429 monografías con un número ISBN asociado. Con ese resultado, podemos construir una gráfica donde se muestra la evolución temporal de la producción anual de monografías dotadas de ese número estándar en España y en ese período de tiempo (figura 7). Según esa gráfica, tras un comienzo titubeante, la publicación de monografías sobre la disciplina en España se dispara en un primer período de 1999 (con la publicación de 2 monografías) a 2004 (con la publicación de 24); un patrón en cierto grado similar al mostrado por la publicación internacional en los corpus en lengua inglesa (figura 5) y en lengua española (figura 6). Sin embargo, y a diferencia de la evolución internacional en las dos lenguas, a continuación se produce un período de aumento (con forma dentada) en la producción anual de volúmenes que culmina en 2012 con la publicación de 54 monografías. Este aumento en el período de 2004 a 2012 puede justificarse por la proliferación de conferencias y congresos relacionados con la disciplina que terminaron generando con sus actas un número importante de monografías con ISBN. Después de 2012, de la misma manera que ocurría en la producción internacional en inglés y español, la publicación en España entra en declive (aunque también con forma dentada) alcanzándose en 2015 una producción de sólo 22 monografías, similar a la que se produjo en 2008.
Producción de artículos científicos

El análisis de la evolución anual de la producción científica sobre la disciplina no estaría completa si no tratáramos también esa misma evolución en la publicación de artículos por parte de investigadores y académicos.

Una buena estrategia para analizar la evolución anual de la producción de artículos científicos es examinar la producción registrada por las principales bases de datos que indizan las revistas donde esos investigadores publican sus aportaciones científicas.

Entre esas bases de datos destacan, por encima del resto, Web of Science y Scopus. Estas bases de datos no recogen toda la producción en forma de artículos realizada por los científicos, pero dan cuenta de una parte importante que, según declaran, se ajusta a unos estándares de calidad establecidos.

Web of Science es una web de las compañías Onex y Baring Private Equity Asia que da acceso a varias bases de datos bibliográficas y recursos de análisis de la información que permiten evaluar y analizar el rendimiento de la investigación. No proporciona el texto completo de los documentos indizados, pero sí herramientas de análisis que permitan valorar su calidad científica.

Si realizamos una doble búsqueda con el término compuesto "knowledge management", primero en el campo Tema y después en el campo Título entre los años 1995 y 2015, obtenemos una serie de datos con los que construir la gráfica recogida en la figura 8. En ella podemos observar como a partir de 1995 aumenta suavemente, de forma casi lineal, la producción anual de artículos que versan sobre el tema de la gestión del conocimiento o que incluyen en su título el nombre en inglés de la disciplina hasta el año 2006. En los tres años posteriores, aumenta de forma ostensible el ritmo de esa producción anual alcanzando su máximo valor en 2009: con 731 artículos indizados que incluyen la expresión "knowledge management" en su título y con 1.810 artículos indizados que tratan sobre el tema de la gestión del conocimiento. Pero es a partir de ese año cuando el número anual de esos dos tipos de artículos comienza a decaer paulatinamente para, tras un pequeño repunte 2013, desplomarse hasta alcanzar en 2015 valores cercanos a los de 2006.

Scopus, por su parte, es la otra gran plataforma de resúmenes y referencias bibliográficas de literatura científica que pertenece a la multinacional Elsevier. Incluye más de 55 millones de registros indizados y el área de humanidades y ciencias sociales se encuentra mejor representada que en la base de datos Web of Science. 
Si realizamos una búsqueda con el término compuesto "knowledge management", en el campo Título (Title) entre los años 1995 y 2015 en Scopus, obtenemos la gráfica de la figura 9, que ofrece un patrón evolutivo muy similar al de la base de datos anterior. En esta nueva figura podemos observar como a partir de 1995 aumenta de forma casi lineal la producción anual de artículos que incluyen en su título el nombre en inglés de la disciplina de la gestión del conocimiento hasta 2003, indizándose ese año 452 documentos en la base de datos. Después de ese período, tras un año (2004) en el que apenas aumenta la producción anual, en 2005 se dobla el número de artículos indizados ese año, alcanzando los 800 documentos. Desde 2005, continua un crecimiento continuado de la producción anual hasta alcanzar, en 2009 y con 1.325 documentos, el punto más alto en esa progresión. Pero es a partir de ese año, como ocurría en Web of Science, cuando el número anual de artículos comienza a desplomarse hasta alcanzar en 2015 (con sólo 863 documentos) valores cercanos a los de 2006 (812 documentos).

Obtenemos resultados muy similares si realizamos la misma búsqueda en esta plataforma, pero esta vez en el campo Palabra clave (Keyword) en lugar del campo Título. Tras esa nueva búsqueda, podemos generar la figura 10. En ella observamos cómo, a partir de 1995, aumenta de forma casi lineal la producción anual de artículos que versan sobre el tema de la gestión del conocimiento hasta 2009, año en el que se indizan 9.223 documentos en esta base de datos. Pero es también a partir de ese año cuando el número anual de artículos decae constantemente hasta alcanzar en 2015 (4.852 documentos producidos) valores similares a los obtenidos en 2006 (4.276 artículos indizados).

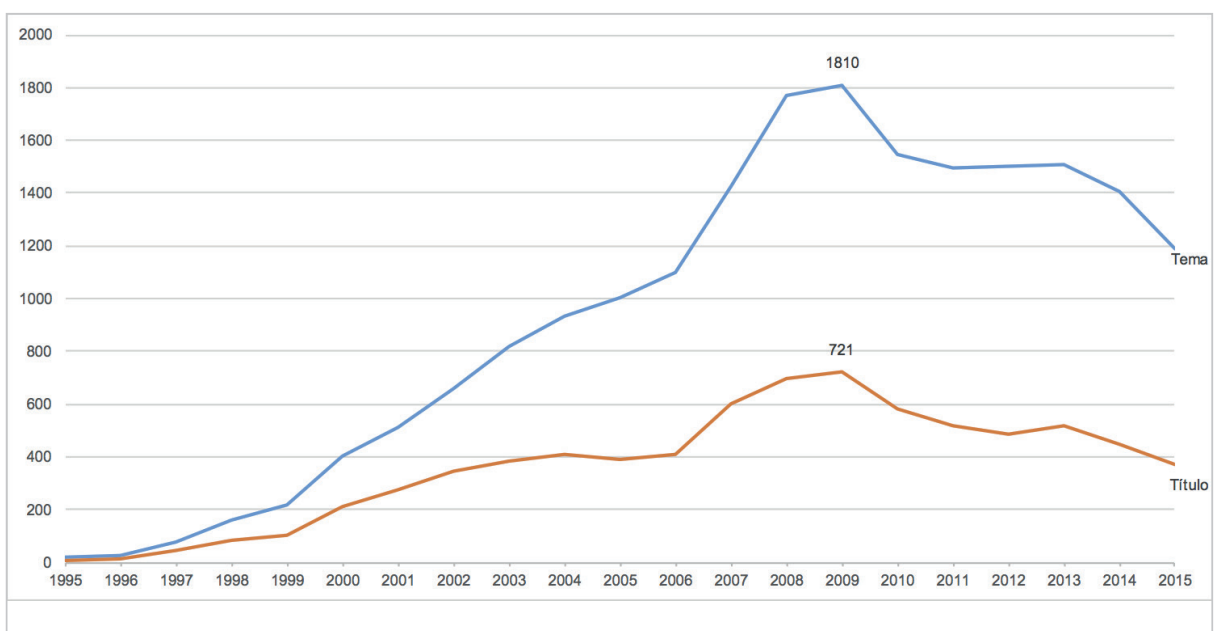

Figura 8. Gráfica obtenida con la búsqueda "knowledge management" (por título y tema) entre los años 1995 y 2015 dentro de la base de datos Web of Science

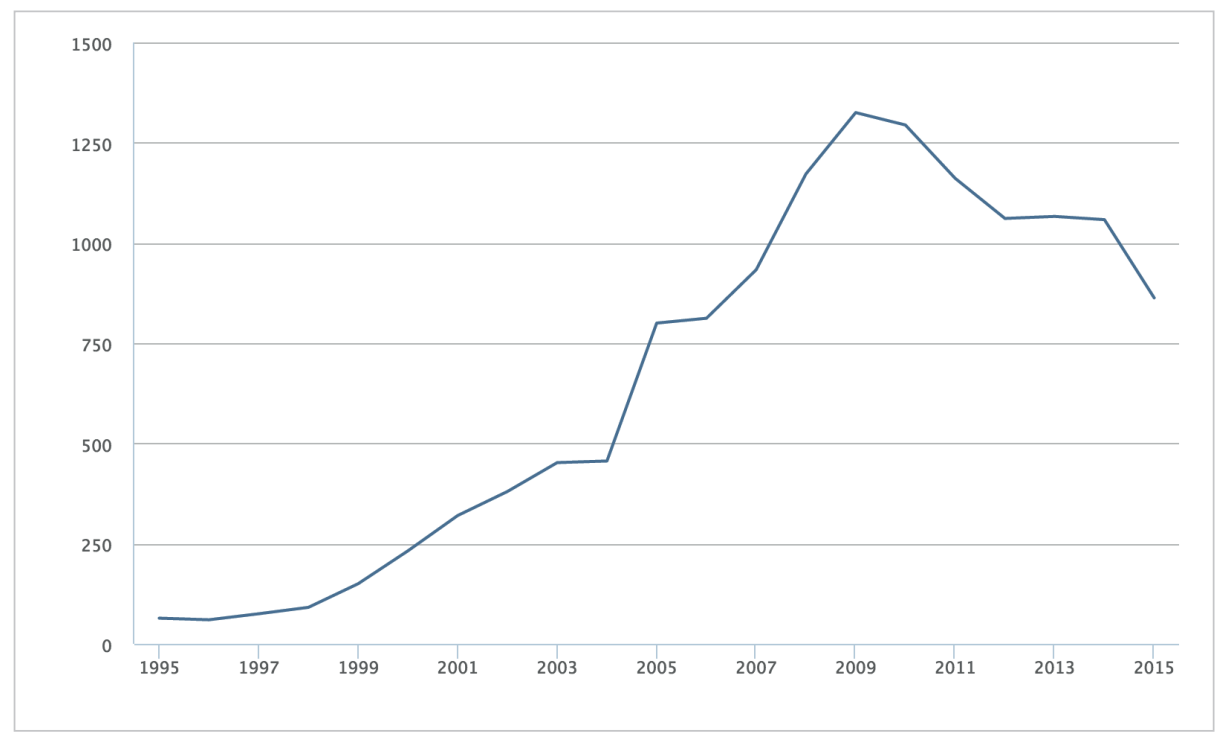

Figura 9. Gráfica obtenida con la búsqueda "knowledge management" (campo Title) entre los años 1995 y 2015 en la base de datos Scopus

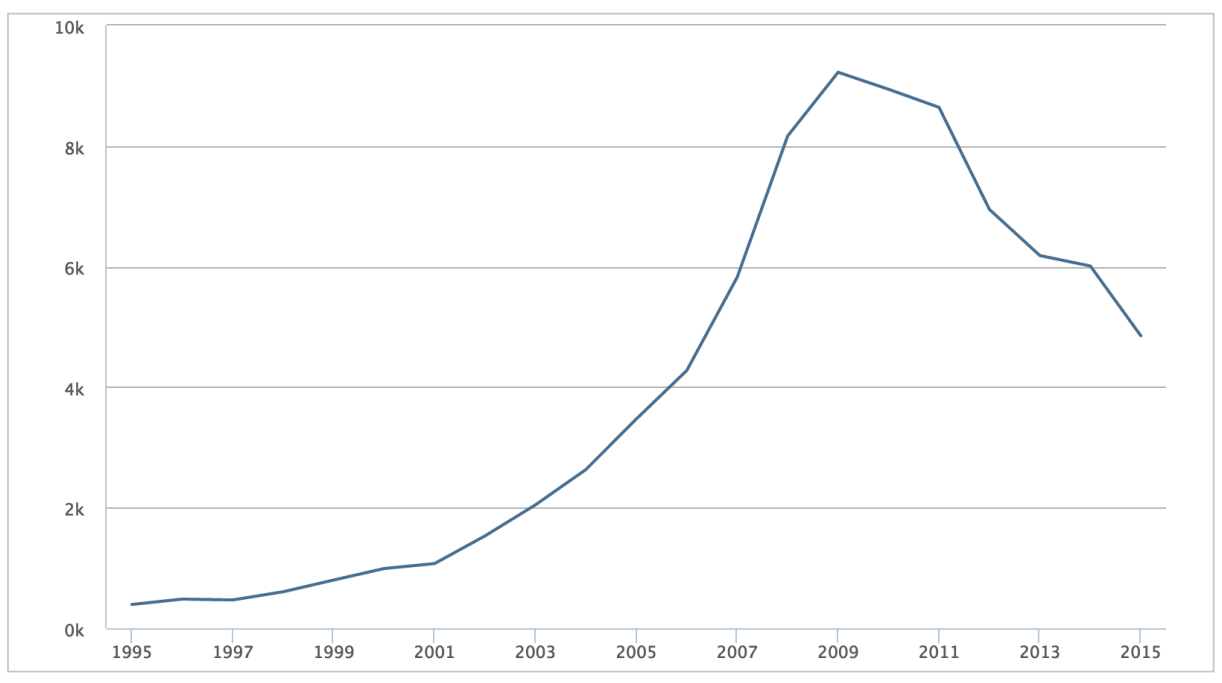

Figura 10. Gráfica obtenida con la búsqueda "knowledge management" (campo Keyword) entre los años 1995 y 2015 en la base de datos Scopus 


\subsection{Formación universitaria}

Completemos el análisis del escenario actual de la disciplina de la gestión del conocimiento abordando también el tema de su formación universitaria.

El tema de la formación sobre gestión del conocimiento es muy extenso, y casi inabarcable en un modo exhaustivo. En el mundo existen actualmente miles de cursos universitarios (grados, masters, doctorados o extensión universitaria, entre otros) que versan directamente sobre la disciplina o que incluyen nociones sobre ese tipo de gestión en algunas de las competencias que adquirirán sus estudiantes una vez cubierto el curso.

Si nos centramos en los cursos o contenidos sobre gestión del conocimiento impartidos dentro de programas universitarios orientados a la formación de profesionales de la información, podemos comprobar que:

- el $47 \%$ de esos cursos se imparte en Norteamérica;

- el $24 \%$ en Oceanía (Australia y Nueva Zelanda);

- el $14 \%$ se imparten en el continente europeo (Roknuzzaman; Umemoto, 2009; Pacios-Lozano; Rueda-Martínez, 2016).

Este contraste de cifras se puede atribuir al mayor grado de control gubernamental existente en Europa respecto al diseño de programas formativos universitarios que suele limitar el catálogo y las competencias de los cursos acreditados.

Pero centrémonos ahora en el ámbito geográfico español. Podemos utilizar recursos online para identificar el volumen y distribución de cursos sobre gestión del conocimiento impartidos actualmente.

Así, por ejemplo, si realizamos en el portal Universia (financiado por el Banco de Santander) una búsqueda con la expresión "gestión del conocimiento" descubriremos que actualmente se imparten 25.497 cursos relacionados directa o indirectamente con esa disciplina (incluidos también algunos, menos del $1 \%$ del total, que forman parte de ciclos superiores de formación profesional). La mayoría se concentran en titulaciones de grado y master de empresariales, marketing, informática o ingeniería; aunque, en la mayoría de esos cursos recuperados, la relación con la disciplina sea muy escasa o tangencial.

http://cursos.universia.es

Algo muy parecido ocurre si realizamos la misma búsqueda en otro portal similar como Educaweb. En este caso, aunque recuperemos sólo 7.203 cursos, el panorama es similar. La mayoría se concentra en la oferta de master y grado en las áreas señaladas y muchos de ellos mantienen una relación indirecta o sólo testimonial con la disciplina.

http://www.educaweb.com

Pero si nos limitamos a identificar la oferta acreditada por el Ministerio español, el panorama cambia de forma radical. El portal de títulos de la Aneca (Agencia Nacional de Evaluación de la Calidad y Acreditación, organismo encargado de la acreditación de las titulaciones universitarias oficiales y reconocidas por el gobierno), tras la misma búsqueda, sólo ofrece 15 resultados (frente a 25.497 y 7.203 de los dos casos anteriores). La diferencia en las cifras de lo recuperado es sustancial. En este caso sólo aparecen 15 programas de master universitario (acreditados por la Agencia) centrados en las mismas áreas destacadas, ninguno de grado, de los cuales 9 son públicos y 6 privados.

\section{http://www.aneca.es}

En el campo de la formación universitaria española relacionada con la ciencia de la información, el escenario de los cursos sobre gestión del conocimiento es muy escueto. Desde 2003, sólo se han diseñado 7 titulaciones (algunas ya desaparecidas) donde se han programado cursos sobre esta materia. En la mayoría de esos cursos la gestión del conocimiento ha sido una materia optativa dentro de sus programas respectivos. A fecha de hoy, sólo están programadas cuatro asignaturas sobre la disciplina, de las cuales 4 son de grado ( 2 optativas y 2 obligatorias), y una sola de máster (Pacios-Lozano; Rueda-Martínez, 2016).

El interés general por la gestión del conocimiento presenta un patrón similar al de otras propuestas que, tras un fuerte ascenso en popularidad, han ido perdiendo la atención general y diluyéndose poco a poco

\section{Conclusiones}

A partir de los datos expuestos, podemos extraer una serie de conclusiones, principalmente, sobre interés general, producción científica y formación. Apuntaremos también, algunas de las posibles causas que pueden explicar las conclusiones.

El interés general por la disciplina de la gestión del conocimiento presenta un patrón similar al de otras propuestas que, tras un fuerte ascenso en popularidad, han ido perdiendo la atención general y diluyéndose poco a poco. Desde mediados de la década de los 90 , el término knowledge management se convirtió en una verdadera buzz word (palabra de moda) con la que se nombraban varias estrategias, algunas veces contradictorias entre sí, de innovación en la gestión organizacional. Sin embargo, ese interés comienza a decaer a partir de 2004 reduciéndose de forma paulatina la atención por esas propuestas hasta nuestros días.

En el campo de la producción científica ocurre algo muy similar al interés general mostrado por la disciplina. En la producción anual de monografías, el descenso comienza también en 2004 en el corpus de libros en inglés y dos años más tarde, en el 2006, en el fondo en lengua española. Centrados en el ámbito exclusivamente nacional, ese descenso no comienza hasta 2012. Sin embargo, en la producción de artículos científicos indizados en las dos principales bases de datos, el año de inflexión donde comienza el descenso de la producción es 2009. Este descenso en la producción científica no se corresponde necesariamente con un abandono total de la dimensión práctica de la disciplina. Frente a cierto agotamiento en las aportaciones científico-conceptuales, en algunos ámbitos profesionales, especialmente en empresas internacionales, las estrategias de gestión del conocimiento se han implantado con éxito e incorporado al propio ADN organizativo. 
En muchas ocasiones, la evolución de la producción científica relacionada con una disciplina no se correlaciona directamente con la formación universitaria ofertada sobre ese tema. Los objetivos monetarios que en muchos casos persigue la formación y el carácter especialmente profesionalizador de sus salidas laborales pueden explicar la existencia de una elevada oferta formativa frente a un descenso paulatino de la producción científica. En todo caso, en términos cuantitativos, la oferta formativa sobre esta disciplina se concentra en territorio norteamericano; y en el caso español destaca la escasa oferta de titulaciones sobre el tema acreditadas por las agencias gubernamentales de evaluación.

No existe una causa única que pueda explicar el ascenso y declive de la disciplina de la gestión del conocimiento. Pero sí que es posible enumerar una serie de factores, relacionados con la propia dimensión cultural y tecnológica de su implementación en las organizaciones, que puedan justificar esa evolución mostrada.

En el ámbito cultural-organizativo destaca, por ejemplo:

- falta de apoyo en la dirección de las organizaciones respecto a los proyectos de este tipo. Sin este apoyo, se han visto abocados al fracaso;

- no se han desarrollado herramientas para la medición, evaluación y control del conocimiento que permitan realizar un análisis y una evaluación adecuada de los proyectos;

- la falta de una clara y transparente política de incentivos que puedan orientar e incentivar a los potenciales participantes y protagonistas de estos proyectos ha limitado también la consolidación de los mismos.

En el terreno tecnológico, las constricciones han sido también importantes. La expansión y consolidación de la disciplina se ha limitado por esa errónea percepción dominante de que la gestión del conocimiento se resume única y exclusivamente a una implantación tecnológica. Tampoco se ha desarrollado un software adecuado (y, por qué no, gratuito) que se haya convertido en un estándar tecnológico en el campo de la implementación. Sin este software, el futuro de la disciplina y sus potenciales beneficios se ha ensombrecido significativamente.

Por último, el hecho de no haber sabido exportar y aplicar decididamente esa disciplina en la administración pública también ha supuesto un freno importante. Esta exportación habría permitido obtener dos importantes beneficios:

- por el especial contexto y problemas que presentan estas organizaciones, esos proyectos se podrían haber convertido en el primer motor del desarrollo teórico-pragmático de la disciplina;

- habría aumentado la popularidad de los mismos al trasladarse directamente al ciudadano todos los importantes beneficios que se obtienen cuando se implementan proyectos de este tipo en las organizaciones encargadas de su administración.

\section{Bibliografía}

Arrow, Kenneth (1962). "The economic implication of learning by doing". Rewiew of economic studies, v. 29, n. 3, p. 153-173.
Davenport, Thomas (1997). Information ecology. Oxford: Oxford University Press. ISBN: 9780195111682

Davenport, Thomas; Prusak, Laurence (1998). Working knowledge. Boston: Harvard Business School Press. ISBN: 9781578513017

Gorey, Rian; Dobat, David R. (1996). "Managing in the knowledge era". The systems thinker, v. 7, n. 8, pp. 1-5. https://thesystemsthinker.com/managing-in-the-knowledgeera

Leonard-Barton, Dorothy (1995). Wellsprings of knowledge: Building and sustaining the sources of innovation. Boston, MA: Harvard Business School Press. ISBN: 9780875848594

Nonaka, Ikujiro (1991). "The knowledge creating company". Harvard business review on knowledge management. Boston: Harvard Business School Publishing, pp. 21-46.

Nonaka, Ikujiro; Konno, Noboru (1998). "The concept of 'Ba': Building a foundation for knowledge creation". California management review, v. 40, n. 3, p. 40-54.

http://home.business.utah.edu/actme/7410/Nonaka\%20 1998.pdf

Nonaka, Ikujiro; Takeuchi, Hirotaka (1995). The knowledge creating company. Oxford: Oxford University Press. ISBN: 9780195092691

Pacios-Lozano, Ana-Reyes; Rueda-Martínez, Isabel (2016). “Una mirada crítica a la formación en gestión del conocimiento en los estudios de información y documentación en España". BiD: textos universitaris de biblioteconomia i documentació, n. 36. http://bid.ub.edu/36/pacios.htm

Prusak, Laurence (2001). "Where did knowledge management came from?". IBM systems journal, v. 40, n. 4, pp. 1002-1007.

http://dx.doi.org/10.1016/S0957-4174(97)00018-3

Roknuzzaman, Md; Umemoto, Katsuhiro (2009). “Knowledge management education in library and information science schools: An exploratory study". En: Preparing information professionals for international collaboration: Asia-Pacific conference on library \& information education \& practice (A-LIEP). Tsukuba, 6-8 March 2009, pp. 27-37.

http://www.slis.tsukuba.ac.jp/a-liep2009/proceedings/ Papers/a48.pdf

Senge, Peter M. (1990). The fifth discipline: The age and practice of the learning organization. London: Century Business. ISBN: 0385260954

Stewart, Thomas A. (1997). Intellectual capital: The new wealth of organizations. New York: Currency/Doubleday. ISBN: 9780385483810

Sveiby, Karl-Erik (1997). The new organizational wealth: Managing and measuring knowledge-based assets. San Francisco: Berrett-Koehler. ISBN: 9781576750148

Sveiby, Karl-Erik (2001). What is knowledge management? Brisbane: Sveiby Knowledge Associates.

http://www.sveiby.com/articles/KnowledgeManagement.html

World Wide Web Consortium (2012). Semantic web use cases and case studies. 